\title{
CAPSULE COMMENTARIES \\ Capsule Commentary on Christian et al.'s “Measuring the Health of an Invisible Population: Lessons from the Colorado Transgender Health Survey"
}

\author{
Candace Girod, MPH and Jeffrey H. Herbst, PhD \\ Division of Violence Prevention, National Center for Injury Prevention and Control, Atlanta, GA, USA.
}

J Gen Intern Med 33(10): 1780

DOI: $10.1007 / \mathrm{s} 11606-018-4569-5$

(C) This is a U.S. government work and not under copyright protection in the U.S.; foreign copyright protection may apply 2018

$\mathrm{T}$ his survey conducted by Christian et al. ${ }^{1}$ aimed to describe transgender individuals' self-rated health and how it relates to their experience of health care systems in Colorado. The electronic survey was developed using questions from the Behavioral Risk Factor Surveillance System (BRFSS) and National Survey on Drug Use and Health (NSDUH) to compare results with those of the general population in Colorado in 2014. Questions from the National Transgender Discrimination Survey (NTDS) were included to capture nuances specific to transgender communities. Random surveys of transgender individuals are complicated due to small size and hard-to-reach nature of the population. To overcome these challenges, researchers collaborated with LGBT-focused organizations, service providers, and universities to disseminate the survey. The 406 respondents were more likely to rate their physical health as fair or poor compared to the general population of Colorado. They also reported significant mental health concerns, including high rates of current depression (43\%), lifetime anxiety (52\%), suicidal thoughts $(36 \%)$, and suicide attempts $(10 \%)$ in the past year. However, respondents who had access to a provider they viewed as trans-inclusive were less likely to have poor physical and mental health compared to those who did not.

The survey was only representative of those who are affiliated with LGBT-focused organizations and out as transgender. As a result, the survey sample is skewed toward younger, whiter, and more urban individuals, which excludes those who may have less access to necessary resources. Previous surveys aimed at measuring the health of transgender populations reported similar limitations. ${ }^{2}$ Despite high levels of health inequities, ${ }^{3}$ Colorado is one of only a few states that specifically

Published online July 12, 2018 measures the health of transgender individuals. This gap represents an opportunity for growth in public health surveillance.

Although the survey indicates a protective factor for transgender individuals is having a knowledgeable health care provider, many providers receive limited training on caring for transgender patients, and few are comfortable engaging with them. ${ }^{4}$ To improve the health and well-being of transgender individuals and to reduce health inequities, additional research is needed to understand barriers and facilitators to providing trans-inclusive health care. ${ }^{5}$

Corresponding Author: Jeffrey H. Herbst, PhD; Division of Violence PreventionNational Center for Injury Prevention and Control, Atlanta, GA, USA (e-mail: jherbst@cdc.gov).

\section{Compliance with Ethical Standards:}

Conflict of Interest: The authors declare that they have no conflicts of interest.

Disclaimer: The findings and conclusions in this article are those of the authors and do not necessarily represent the official position of the Centers for Disease Control and Prevention.

\section{REFERENCES}

1. Christian R, Mellies AA, Bui AG, Lee R, Kattari L, Gray C. Measuring the health of an invisible population: lessons from the Colorado Transgender Health Survey. J Gen Intern Med. 2018. https://doi.org/10.1007/ s11606-018-4450-6

2. Dickey LM, Hendricks ML, Bockting Wo. Innovations in research with transgender and gender nonconforming people and their communities. Psychol Sex Orient Gender Divers. 2016;3(2):187-194. https://doi.org/10. $1037 /$ sgd0000158

3. Hughto JMW, Reisner SL, Pachankis JE. Transgender stigma and health: a critical review of stigma determinants, mechanisms, and interventions. Soc Sci Med. 2015;147:222-231. https://www.sciencedirect.com/science/article/pii/S0277953615302185

4. Stroumsa D. The state of transgender health care: policy, law, and medical frameworks. Am J Public Health. 2014;104(3):e31-e38. https://ajph. aphapublications.org/doi/abs/10.2105/AJPH.2013.301789

5. Safer JD, Coleman E, Feldman J, Garofalo R, Hembree W, Radix A, Sevelius J. Barriers to health care for transgender individuals. Curr Opin Endocrinol Diabetes Obes. 2016;23(2):168-171. https://www.ncbi.nlm. nih.gov/pmc/articles/PMC4802845/ 